\title{
COMPILING TECHNIQUES FOR EAST ANTARCTIC ICE VELOCITY MAPPING BASED ON HISTORICAL OPTICAL IMAGERY
}

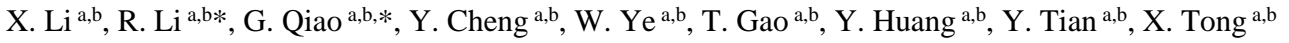 \\ ${ }^{\text {a }}$ Center for Spatial Information Science and Sustainable Development, Tongji University, 1239 Siping Road, Shanghai, China \\ ${ }^{\mathrm{b}}$ College of Surveying and Geo-Informatics, Tongji University, 1239 Siping Road, Shanghai, China
}

Commission III, WG III/9

KEY WORDS: East Antarctica, Ice Flow Velocity, Optical Images, Mapping

\begin{abstract}
:
Ice flow velocity over long time series in East Antarctica plays a vital role in estimating and predicting the mass balance of Antarctic Ice Sheet and its contribution to global sea level rise. However, there is no Antarctic ice velocity product with large space scale available showing the East Antarctic ice flow velocity pattern before the 1990s. We proposed three methods including parallax decomposition, grid-based NCC image matching, feature and gird-based image matching with constraints for estimation of surface velocity in East Antarctica based on ARGON KH-5 and LANDSAT imagery, showing the feasibility of using historical optical imagery to obtain Antarctic ice motion. Based on these previous studies, we presented a set of systematic method for developing ice surface velocity product for the entire East Antarctica from the 1960s to the 1980s in this paper.
\end{abstract}

\section{INTRODUCTION}

The mass balance change of Antarctic ice sheet as a response to climate change is of great significance in estimating its contribution to the global sea level rise. However, there are a number factors that affect the quantitative precision of the estimation and thus causes uncertainty of the sea level change computation. Large part of the ice and sediments loss of the Antarctic ice sheet is through the ice flow discharge into the ocean (Bennett, 2003). Consequently, ice flow velocity is an essential parameter in calculating ice flux and then assessing the mass balance of Antarctic ice sheet.

Early Antarctic ice flow velocity measurements began in the 1950 s, using theodolites or other ranging instruments to measure displacements and moving speed of reference markers on the glacial surface (Dorrer et al., 1969). Since the 1980s, GNSS techniques have largely replaced traditional survey measurements to derive the ice surface motion (Frezzotti et al., 1998; Manson et al., 2000; Urbini et al., 2008) and the accuracy and efficiency of the measurements have been greatly improved. However, these in-situ measurements require considerable time and efforts, and only small-scale measurements can be accomplished due to the limitations of observation stations and harsh environment.

The development of satellite remote sensing-based observations using Interferometric Synthetic Aperture Radar (InSAR) technology (Goldstcin et al., 1993) and optical images based feature tracking technique (Scambos et al., 1992) has largely overcome these limitations, making it possible to monitor the ice sheet wide ice motion.

Goldstein et al. (1993) firstly used D-InSAR technology based ERS-1 images to detect the velocity in Rutford glacier and achieve a high level of accuracy. The first surface velocity map of the entire Antarctic ice sheet from 1996 to 2009 also used a combination of multiple SAR images from different satellites (Rignot et al., 2011), showing the spatial pattern of modern ice flow distribution across the Antarctic continent. Tong et al. (2017) analyzed the ice motion of Amery Ice Shelf based on differential and multiple-aperture InSAR. Compared with the measurement using optical images, InSAR is of high accuracy and spatial resolution, but the available data in Antarctic area is mainly limited to after 1990s.

The main idea of ice flow measurement based on optical images is using feature tracking technique and correlation calculation principle to obtain the corresponding points in two satellite images acquired at different times. Early studies used visualization to manually track glacier surface features to obtain ice displacements (Lucchitta et al., 1986). Since the 1990s, with the introduction of image matching algorithms, the accuracy and efficiency of ice flow velocity measurements using automated feature tracking techniques have been greatly enhanced. The research on this method mainly focuses on the image matching method (Scambos et al., 1992; Whillans et al., 1995; Leprince et al., 2007; Liu et al., 2012). Heid et al. (2011) reviewed six of the most commonly used matching methods and set the evaluation criteria to assess the reliability of these matching methods and the adaptability to different images. The use of optical remote sensing images for measurement has the advantages of low cost, rich historical data and large coverage. Although its measurement accuracy is inferior to InSAR to some extent, some methods can be used to reduce the errors and improve the measurement accuracy.

There is no velocity product covering the entire Antarctica before the 1990s. Li et al. (2017a and b, Ye et al. 2017) presented three methods including parallax decomposition, grid-based NCC image matching, feature and gird-based image matching with constraints for estimation of surface velocity of some glaciers in East Antarctica from the 1960s to the 1980s based on ARGON KH-5 and LANDSAT imagery, showing the feasibility of using historical optical imagery to obtain Antarctic ice motion. Based on these previous studies, this paper presents a set of systematic

\footnotetext{
* Corresponding author
} 
map compiling methods of developing ice surface velocity products for the entire East Antarctica area based on historical optical images from the 1960s to the 1980s.

\section{MAPPING PROCESS}

\subsection{Coordinate system and projection}

Selection of appropriate coordinate system and projection for visualization is the basis of mapping. In this paper, we selected polar stereographic (south) projection with $71^{\circ} \mathrm{S}$ as the standard latitude and WGS-84 ellipsoid which are mostly used in Antarctic regions. This projection can represent local shapes with less distortions in Antarctica, so it is ideal for drawing hemispherical, continental and mid-scale maps (such as the entire Antarctic map).

\subsection{Selection of image pairs}

The cloud coverage, time interval and resolution of image pairs should be taken into account when using surface features of optical images to match the corresponding points and track the ice mass displacement. In order to ensure the quality of the result, we select the images with less cloud and no occlusion. We select the image pair with a proper time interval $t$ according to the following equation:

$$
\begin{array}{ll}
\qquad \mathrm{d}=\frac{\mathrm{v} * \mathrm{t}}{\mathrm{r}} \\
\text { where } \\
\mathrm{d}=\text { ice displacement (pixel) } \\
\mathrm{v}=\text { predicted velocity } \\
\mathrm{t}=\text { time interval of the image pair } \\
\mathrm{r}=\text { image resolution }
\end{array}
$$

Generally, it is optimal to control ice displacement within 5-15 pixels according to the previous experiments. For example, for the areas with fast ice flow (such as more than $600 \mathrm{~m} / \mathrm{yr}$ ), image pairs with a time interval of around 1 year can be used if the resolution is $60 \mathrm{~m}$. For areas with a slower ice flow speed, a longer interval may be needed.

\subsection{Pre-processing and orthorectification}

Early satellite images are usually of poor quality and contain geometric distortions so that they cannot be used directly in image matching. Consequently, various image enhancement techniques, such as histogram equalization, are used to improve feature extraction and matching. In addition, we used the obvious feature points in the bare rock area as basic controls and the Toutin's model (Toutin, 2004) in the commercial software PCI to ortho-rectify remote sensing images, using the Landsat Image Mosaic of Antarctic (LIMA) and the RADARSAT Antarctic Mapping Project (RAMP) digital elevation model as reference points.

\subsection{Image matching}

Image matching is the key step in the ice velocity estimation based on optical images. In this paper, we used three methods of image matching proposed by $\mathrm{Li}$ et al. (2017a and b) including parallax-decomposition-based hierarchically image matching for ARGON image pairs in the 1960s, grid-based NCC image matching for LANDSAT 4/5 image pairs in the 1970s and 1980s, and feature and grid-based image matching with constraints for ARGON \& LANDSAT MSS image pairs and LANDSAT MSS $\&$ TM image pairs over a long time period.

\subsection{Quality inspection}

We have identified some indicators for the quality check of ice flow matching results. The first is the location of ice flow, which tends to occupy topographic lows. Moreover, whether the speed and direction of ice flow are in line with the ice moving features in the images can also be used for quality inspection. The ice flow in each major drainage basin is limited within the basin and mainly flow in and out its main and tributary glaciers, and further into the ocean. Therefore, the mapped speed and direction data have to be consistent with these patterns.

\subsection{Precision analysis}

The accuracy of the ice flow velocity measurements varies with the sensor, geographical location, and time period of the image pair used. The main sources of errors are ortho-rectification error and image matching error. According to the statistical results of manual inspection based on obvious surface features on the ice sheet, the accuracy of the estimated ice displacement from different data sources is shown as Table 1 where image pairs are combined ARGON, MSS and TM LANDSAT images, and KIM (mosaic assembled from ARGON images by Kim, 2007). The error of the estimated ice flow velocity is the total error divided by the time interval of the image pairs.

Table 1. Estimated Error for each type of image pair

\begin{tabular}{|c|c|c|c|}
\hline Type of Image pair & $\begin{array}{c}\text { Rectification } \\
\text { Error }\end{array}$ & $\begin{array}{c}\text { Matching } \\
\text { Error }\end{array}$ & $\begin{array}{c}\text { Total } \\
\text { Error }\end{array}$ \\
\hline ARGON \& ARGON & $\mathrm{m}$ & $\mathrm{m}$ & $\mathrm{m}$ \\
ARGON \& MSS & 102.30 & & \\
KIM \& MSS & 44.00 & 65.01 & 120.95 \\
LANDSAT MSS & 41.59 & 40.04 & 56.88 \\
LANDSAT MSS \& TM & 33.13 & 39.99 & 58.20 \\
LANDSAT TM & 21.58 & 22.60 & 51.93 \\
\hline
\end{tabular}

\subsection{Interpolation}

Because the matching points cannot completely cover every location in the study area, it is necessary to create a continuous surface of ice flow field by interpolation. There are a variety of ways referring to different models for interpolation. We chose Kriging and Natural Neighbour Interpolation in ArcGIS to produce an ice flow velocity map. Kriging is an advanced geostatistical procedure which uses a fitting function for a specified number of points or all points within a specified radius, to determine the predicted value. Natural Neighbour interpolates a value according to the values with weights of the closest subsets of existing points. The advantage of Kriging algorithm is that it takes spatial statistics as its solid theoretical basis, but its calculation is time-consuming with high total number of input points and the function sometimes needs to be selected based on experience. Consequently, for different areas with different points amount and ice flow distribution, we chose the more suitable one of these two methods to interpolate.

In addition to the interpolation method, we also used point density that is defined as the average ratio of the number of matched points over the occupied area to determine the proper resolution of the entire raster map. Due to the various accuracies of results from different satellite imagery, we calculated five point densities for different data source categories and determined two resolutions of $650 \mathrm{~m}$ and $1000 \mathrm{~m}$ respectively. 


\subsection{Mosaicking}

The results and accuracy of the ice velocity measurement are affected by the sensor, resolution, cloudiness, noise and the time interval of the image pair. Therefore, it needs some considerations to mosaic the results of ice velocity map from different data sources. In this research, we choose images with the similar time period to establish image pairs for mapping regions with a certain ice flow speed. Furthermore, the matched points obtained from the same data source can be interpolated together. Areas with matched points from different data sources are required to overlap margins between areas. The areas can be mosaicked into the overall map only when the inconsistencies in the margins are sufficiently small to ensure a high quality of the map.

\section{DATA AND EXPERIMENTS}

Based on the above procedure, we obtained an initial result of a map of ice flow velocity with a defined reference frame and resolution. Our study area is the entire East Antarctica covered by early images from the 1960 s to the 1980 s.

Here, we take Amery Ice Shelf, Rayner Glacier, and Shackleton Ice Shelf as examples shown in Figure 1.

The process mentioned above was performed for ice flow velocity mapping based on five type of images pairs including: (1) ARGON images pairs in 1963, (2) ARGON and LANDSAT (MSS) image pairs from the 1960s to the 1970s, (3) LANDSAT (MSS) images pairs in the 1970s, (4) LANDSAT (MSS \& TM) image pairs from the 1970s to the 1980s, (5) LANDSAT (TM) image pairs in the 1980s. Compared with existing ice flow velocity map from 1996 to 2009 in the entire Antarctica by Rignot et al. (2011), we found that the ice flow velocity in the main ice flow area of the Amery Ice Shelf did not change significantly over the two periods. The ice flow velocity in the front of the Shackleton Ice Shelf was 100-200 m/yr slower than the results measured by Rignot et al. (2011).

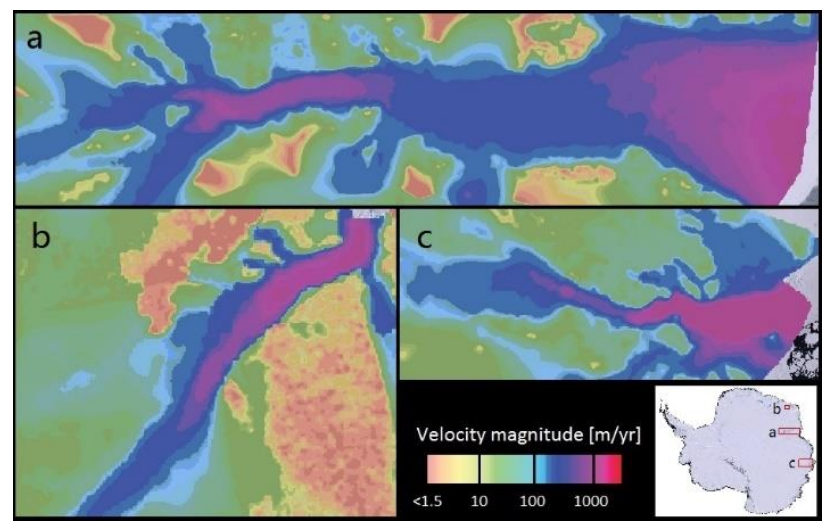

Figure 1. Ice velocity mapping results of selected glaciers from 1960s to the 1980s. (a) Amery Ice Shelf, (b) Rayner Glacier, and (c) Shackleton Ice Shelf.

\section{DISCUSSIONS AND FUTURE WORK}

In this paper, a set of systematic map compiling techniques is proposed for generating an ice flow velocity map of 1960s-1980s in East Antarctica based on early ARGON and LANDSAT imagery. The developed methods can be used for large scale Antarctic ice flow mapping using heterogeneous satellite data acquired at various resolutions, time periods, and accuracies The choice of remote sensing imagery is extremely important and the suitable interpolation method should be selected according to the quality and density of different matching points. Our goal is to produce an ice flow map of the entire East Antarctica from 1960s to 1980 s. We are in the final stage of the product generation.

\section{ACKNOWLEDGEMENTS}

This work has been supported by the National Key Research \& Development Program of China (No. 2017YFA0603102) and National Key Basic Research Program of China (No. 2012CB957701).

\section{REFERENCES}

Bamber, J. L., Vaughan, D. G., \& Joughin, I., 2000. Widespread complex flow in the interior of the Antarctic ice sheet. Science, 287(5456), pp. 1248-1250.

Bennett, M. R., 2003. Ice streams as the arteries of an ice sheet: their mechanics, stability and significance. Earth Science Reviews, 61, pp. 309-339.

Dorrer, E., Hofmann, W., \& Seufert, W., 1969. Geodetic results of the Ross Ice Shelf Survey expeditions, 1962-63 and 1965-66. Journal of Glaciology, 8(52), pp. 67-90.

Frezzotti, C. E., Alessandro, C., \& Vittuari, L., 1998. Comparison between glacier ice velocities inferred from GPS and sequential satellite images. Annals of Glaciology, 27(1), pp. 54-60.

Fricker, H. A., Coleman, R., Padman, L., Scambos, T. A., Bohlander, J., \& Brunt, K. M., 2009. Mapping the grounding zone of the Amery Ice Shelf, East Antarctica using InSAR, MODIS and ICESat. Antarctic Science, 21(5), pp. 515-532.

Goldstein, R. M., Engelhardt, H., Kamb, B., \& Frolich, R. M., 1993. Satellite radar interferometry for monitoring ice sheet motion: application to an Antarctic ice stream. SCIENCE-NEW YORK THEN WASHINGTON-, 262, pp. 1525-1525.

Heid, T., \& Kääb, A., 2012. Evaluation of existing image matching methods for deriving glacier surface displacements globally from optical satellite imagery. Remote Sensing of Environment, 118, pp. 339-355.

Kim, K., Jezek, K. C., \& Liu, H., 2007. Orthorectified image mosaic of Antarctica from 1963 Argon satellite photography: image processing and glaciological applications. International Journal of Remote Sensing, 28(23), pp. 5357-5373.

Leprince, S., Ayoub, F., Klinger, Y., \& Avouac, J. P., 2007. Coregistration of optically sensed images and correlation (COSICorr): An operational methodology for ground deformation measurements. In Geoscience and Remote Sensing Symposium, 2007. IGARSS 2007. IEEE International, pp. 1943-1946).

Li, R., Ye, W., Kong, F., Qiao, G., Tong, X., Ma, X., ... \& Wang, Z., 2016. A Novel Method for Estimation of Glacier Surface Motion in 1960s from Argon KH-5 Optical Imagery. ISPRSInternational Archives of the Photogrammetry, Remote Sensing and Spatial Information Sciences, XLI-B8, pp. 521-524.

Li, R., Ye, W., Qiao, G., Tong, X., Liu, S., Kong, F., \& Ma, X., 2017a. A New Analytical Method for Estimating Antarctic Ice Flow in the 1960s From Historical Optical Satellite Imagery. IEEE Transactions on Geoscience and Remote Sensing, 55(5), pp. 2771-2785. 
Li, R., Ma, X., Cheng, Y., Ye, W., Guo, S., Tang, G., ... \& Qiao, G., 2017b. Ice Velocity Measurement in East Antarctica from 1960s to 1980s Based on Argon and Landsat Imagery. ISPRSInternational Archives of the Photogrammetry, Remote Sensing and Spatial Information Sciences, XLII-2/W7, pp. 1535-1539.

Liu, H., Wang, L., Tang, S. J., \& Jezek, K. C., 2012. Robust multi-scale image matching for deriving ice surface velocity field from sequential satellite images. International journal of remote sensing, 33(6), pp. 1799-1822.

Lucchitta, B. K., \& Ferguson, H. M., 1986. Antarctica: measuring glacier velocity from satellite images. Science, 234, pp. 11051109.

Manson, R., Coleman, R., Morgan, P., \& King, M., 2000. Ice velocities of the Lambert Glacier from static GPS observations. Earth, planets and space, 52(11), pp. 1031-1036.

Mouginot, J., Rignot, E., \& Scheuchl, B., 2014. Sustained increase in ice discharge from the Amundsen Sea Embayment, West Antarctica, from 1973 to 2013. Geophysical Research Letters, 41(5), pp. 1576-1584.

Rignot, E., 2008. Changes in West Antarctic ice stream dynamics observed with ALOS PALSAR data. Geophysical Research Letters, 35(12).

Rignot, E., Mouginot, J., \& Scheuchl, B., 2011. Ice flow of the Antarctic ice sheet. Science, 333(6048), pp. 1427-1430.

Scambos, T. A., Dutkiewicz, M. J., Wilson, J. C., \& Bindschadler, R. A., 1992. Application of image cross-correlation to the measurement of glacier velocity using satellite image data. Remote sensing of environment, 42(3), pp. 177-186.

Tong, X., Liu, S., Li, R., Xie, H., Liu, S., Qiao, G., ... \& Ye, Z., 2018. Multi-track extraction of two-dimensional surface velocity by the combined use of differential and multiple-aperture InSAR in the Amery Ice Shelf, East Antarctica. Remote Sensing of Environment, 204, pp.122-137.

Toutin, T., 2004. Geometric processing of remote sensing images: models, algorithms and methods. International journal of remote sensing, 25(10), pp. 1893-1924.

Urbini, S., Frezzotti, M., Gandolfi, S., Vincent, C., Scarchilli, C., Vittuari, L., \& Fily, M., 2008. Historical behaviour of Dome C and Talos Dome (East Antarctica) as investigated by snow accumulation and ice velocity measurements. Global and planetary change, 60(3), pp. 576-588.

Whillans, I. M., \& Tseng, Y. H., 1995. Automatic tracking of crevasses on satellite images. Cold Regions Science and Technology, 23(2), pp. 201-214.

Ye, W., Qiao, G., Kong, F., Ma, X., Tong, X., \& Li, R., 2017. Improved Geometric Modeling of 1960s KH-5 ARGON Satellite Images for Regional Antarctica Applications. Photogrammetric Engineering \& Remote Sensing, 83(7), pp. 477-491. 